\title{
Upper Brachial Plexus Palsy (Rucksack Palsy)
}

Sam Nahas*, Clarence Yeoh and Hagen Jahnich

Department of Trauma and Orthopaedics, Tunbridge Wells Hospital, Tunbridge Wells, UK

*Corresponding author: Sam Nahas, Department of Trauma and Orthopaedics, Tunbridge Wells Hospital, Tunbridge Wells, Pembury, Kent TN2 QF, UK, Tel: +01895238282; Fax: +01892634829; E-mail: sam.nahas@nhs.net

Rec date: February 27, 2018; Acc date: March 27, 2018; Pub date: March 29, 2018

Copyright: @ 2018 Nahas S, et al. This is an open-access article distributed under the terms of the creative commons attribution license, which permits unrestricted use, distribution, and reproduction in any medium, provided the original author and source are credited.

\begin{abstract}
Rucksack palsy is an uncommon injury presumably caused by prolonged traction of the straps of a backpack on the brachial plexus. We present a patient with painless weakness and loss of sensation in her arm. Familiarity with the differential diagnosis of insidious, painless shoulder weakness is essential in managing patients with rucksack palsy. These patients should be treated expectantly and monitored closely.
\end{abstract}

Keywords: Rucksack palsy; Pack palsy; Upper brachial plexus palsy; Shoulder weakness; Painless

\section{Introduction}

Rucksack palsy is an uncommon injury presumably caused by prolonged traction with the straps of a pack on the brachial plexus. We demonstrate a case of upper brachial plexus palsy caused by carrying a heavy rucksack.

\section{Case Report}

A 14-year-old schoolgirl presented to the fracture clinic complaining of painless weakness in her arm and loss of feeling. This was after an expedition 'test' in preparation for a trekking tour. During the exercise, she was carrying a heavy rucksack, loaded with extra weights.

The upper limb neurological examination demonstrated dysesthesia at the C5 and C6 dermatomes. Her muscle power was normal in trapezius, pectoralis major, triceps, wrist extensor, wrist flexors, interossei and the deltoid.

She did have weakness in the supraspinatus, with Medical Research Council (MRC) grade 4, and MRC grade 2 for subscapularis, infraspinatus and biceps brachia. It is likely that these symptoms resulted from a mechanical injury causing neurapraxia to the upper trunk of the brachial plexus. She was advised against carrying a rucksack on the affected shoulder but encouraged to mobilize the shoulder [1].

A nerve conduction study (NCS) was performed 4 weeks post injury and the result confirmed an upper plexus lesion. Electromyogram (EMG) also showed denervated biceps, brachioradial is, supinator, and extensor carpi radialis longus. She was reviewed 4 weeks post NCS and she continued to recover with improvement of her subscapularis, infraspinatus and biceps brachia to MRC grade 4 [2].

\section{Discussion}

Rucksack palsy is more commonly reported in military personnel during training. The incidence is around 53.7 per 100,000 recruits per year, as reported by the Military Medicine, Finnish Defense Forces [3].
The brachial plexus is protected against mild traction injury by the plexiform pattern and the connective tissue surrounding the nerve fibers, which dissipates any applied force. With prolonged carrying of a heavy pack, the anterior shoulder straps constantly pull the shoulders posteriorly. As a result of extension with added adduction of the arm, the action puts the upper trunks of the brachial plexus at greater risk of traction injury [2].

Clinically rucksack palsy presents as a unilateral lesion. They present with weakness, sometimes with atrophy, dysesthesia and sensory loss [1]. Pain is rarely present. It commonly involves the upper trunk of the brachial plexus but mononeuropathies including spinal accessory, axillary and long thoracic nerve neuropathies can also occur [4].

Improvement in rucksack design by using a frame and hip belt has been demonstrated to reduce the incidence of rucksack palsy. The prognosis is good with $90 \%$ recovery rate within 3 months due to remyelination of the nerve fibers.

Differential diagnoses include thoracic outlet syndrome, brachial plexus neuritis, rotator cuff tear and cervical radiculopathy. The latter 3 problems usually present with pain [5].

\section{Conclusion}

Familiarity with the presentation of insidious onset of painless shoulder weakness aids in managing patients with rucksack palsy. These patients should be treated expectantly and monitored closely. Appropriate and timely referrals to an orthopedic surgeon should also be considered at the earliest stage.

\section{References}

1. De Luigi AJ, Pasquina P, Dahl E (2008) Rucksack induced plexopathy mimicking a lateral antebrachial cutaneous neuropathy. AM J Phy Med Rehabil 87: 773-775.

2. Ferenz CC (1998) Review of the brachial plexus. Part 1: Acute injuries. Orthopedics 11: 479-486.

3. Makela JP, Ramstad R, Mattila V, Philajamaki H (2006) Brachial plexus lesions after backpack carriage in young adults. Clin Orthop Relat Res 452: 205-209.

4. Maurya S, Singh M, Bhandari PS, Bhatti TS (2009) Backpack brachial plexus palsy. Indian Journal of Neurotrauma 6: 153-154. 
Citation: Nahas S, Yeoh C, Jahnich H (2018) Upper Brachial Plexus Palsy (Rucksack Palsy). J Trauma Treat 7: 419. doi: 10.4172/2167-1222.1000419

Page 2 of 2

5. Vath SA, Owens BD, Stoneman PD (2007) Insidious onset of shoulder girdle weakness. J Orthop Sports Phys Ther 37: 140-147. 